\title{
Decoy receptor 3 regulates the expression of tryptophan hydroxylase 1 in rheumatoid synovial fibroblasts
}

\author{
TOSHIHISA MAEDA ${ }^{1}$, YASUSHI MIURA ${ }^{1,2}$, KOJI FUKUDA $^{1,3}$, \\ SHINYA HAYASHI $^{1}$ and MASAHIRO KUROSAKA ${ }^{1}$
}

\begin{abstract}
${ }^{1}$ Department of Orthopaedic Surgery, Kobe University Graduate School of Medicine, Chuo, Kobe, Hyogo 650-0017;
${ }^{2}$ Division of Orthopedic Science, Department of Rehabilitation Science, Kobe University Graduate School of Health Sciences, Kobe, Hyogo 654-0142; ${ }^{3}$ Department of Orthopaedic Surgery, Kakogawa City Hospital, Kakogawa, Hyogo 675-8611, Japan
\end{abstract}

Received October 2, 2014; Accepted June 11, 2015

DOI: $10.3892 / \mathrm{mmr} .2015 .4097$

\begin{abstract}
Decoy receptor 3 (DcR3) is expressed in rheumatoid arthritis fibroblast-like synoviocytes (RA-FLS) and downregulates the expression of tryptophan hydroxylase 1 (TPH1), which is the rate-limiting enzyme in serotonin synthesis. The aim of the present study was to determine the specificity of the effects of DcR3 on TPH1 in RA-FLS, and therefore determine whether DcR3 had the potential to modulate the pathogenesis of RA. The present study also aimed to compare the effects of DcR3 and inflammatory cytokines on the expression of TPH1 in RA-FLS and osteoarthritis (OA)-FLS. Primary cultured RAor OA-FLS were incubated with $1.0 \mu \mathrm{g} / \mathrm{ml} \mathrm{DcR3-Fc} \mathrm{protein}$ or $1.0 \mu \mathrm{g} / \mathrm{ml}$ control immunoglobulin $\mathrm{G}(\operatorname{IgG}) 1$ for $12 \mathrm{~h}$, or with $1.0 \mathrm{ng} / \mathrm{ml}$ tumor necrosis factor (TNF) $\alpha, 1.0 \mathrm{ng} / \mathrm{ml}$ interleukin (IL)-1 $\beta$ or serum-free Opti-MEM only, for $24 \mathrm{~h}$. The relative mRNA expression levels of $T P H 1$ were subsequently quantified using reverse transcription-polymerase chain reaction. The expression of serotonin in RA or OA synovial tissue was detected using immunohistochemistry. The mRNA expression of TPH1 was observed in both RA- and OA-FLS and was significantly decreased following treatment with DcR3 in the RA-FLS, however, not in the OA-FLS. The mRNA expression of TPH1 was significantly decreased following treatment with TNF $\alpha$ or IL-1 $\beta$ in both the RA- and OA-FLS. The expression of serotonin in the multi-layered lining synovial cells of RA and the outer layer lining synovial cells of OA was detected using immunohistochemistry. The present study is the first, to the best of our knowledge, to demonstrate that the expression of TPH1 in FLS is downregulated by inflammatory cytokines, and that DcR3 suppressed the expression of TPH1 in RA-FLS
\end{abstract}

Correspondence to: Dr Yasushi Miura, Division of Orthopedic Science, Department of Rehabilitation Science, Kobe University Graduate School of Health Sciences, 7-10-2 Tomogaoka, Kobe, Hyogo 654-0142, Japan

E-mail: miura@kobe-u.ac.jp

Key words: rheumatoid arthritis, fibroblast-like synoviocyte, decoy receptor 3, tryptophan hydroxylase, serotonin in a disease-specific manner. These results suggested that synovial serotonin may be involved in the pathogenesis of RA, and that TPH1 and DcR3 may be potential therapeutic targets for the treatment of RA.

\section{Introduction}

Rheumatoid arthritis (RA) is an autoimmune, inflammatory joint disease, characterized by hyperplasia of the synovial tissue and the formation of pannus tissue, which grows invasively into the cartilage, causing cartilage and bone destruction. Synovium is composed of two types of synoviocytes: fibroblast-like synoviocytes (FLS) and macrophage-like synoviocytes. Analyses of hyperplastic synovial tissue from patients with RA demonstrated the presence of cells with numerous features similar to transformed long-living cells, including the presence of somatic mutations, oncogene expression and resistance to apoptosis (1-5).

Our previous study demonstrated that decoy receptor 3 (DcR3), termed TR6/M68/tumor necrosis factor receptor (TNFR) superfamily member 6 , is expressed in RA-FLS, and that tumor necrosis factor (TNF) $\alpha$-induced expression of DcR3 in RA-FLS protects the cells from Fas-induced apoptosis (6). DcR3 lacks the transmembrane domain of conventional TNFRs and can, therefore, be secreted (7). DcR3 is typically overexpressed in tumor cells and is also expressed in certain types of normal tissue, including the colon, stomach, spleen, lymph nodes, spinal cord, pancreas and lungs $(7,8)$. DcR3 exerts numerous biological roles, including osteoclast formation (9), monocyte adhesion (10) and inhibition of apoptosis (11).

DcR3 has three ligands: Fas ligand (FasL), LIGHT, and TNF-like ligand 1A (TL1A), all of which are members of the TNF superfamily (12). The overexpression of DcR3 may benefit tumors by helping them to avoid the cytotoxic and regulatory effects of FasL (7,13), LIGHT (14), and TL1A (15). Our previous study suggested that DcR3 may be one of the key molecules, which regulates RA-FLS proliferation (6). In addition, our previous study reported that DcR3 can bind to membrane-bound TL1A, which is expressed on RA-FLS, resulting in the negative regulation of inflammatory cytokine-induced cell proliferation (16). These results suggested 
that DcR3 may have a role in the pathogenesis of RA, not only as a decoy receptor, but also as a ligand for TL1A on RA-FLS.

By comprehensive genetic analysis using microarrays, our previous study demonstrated that DcR3 may regulate gene expression in RA-FLS (17). From these gene expression profiles, tryptophan hydroxylase 1 (TPH1) was identified as one of the genes whose expression was suppressed in RA-FLS by DcR3 (17). TPH catalyzes the hydroxylation of L-tryptophan, and is the rate-limiting enzyme for the synthesis of serotonin. TPH has two isoforms: TPH1, which is expressed in peripheral tissues expressing serotonin, including the skin, and in the intestine, the pineal gland and the central nervous system (CNS); and TPH2, which is exclusively expressed in the CNS where it predominates over TPH1. Numerous previous studies have suggested that serotonergic systems have an important role in modulating inflammatory pain and bone remodeling (18-20).

The aim of the present study was to determine the specificity of the effects of DcR3 on TPH1 in RA-FLS and therefore, determine whether DcR3 had the potential to modulate the pathogenesis of RA. The present study also aimed to compare the effects of DcR3 and inflammatory cytokines on the expression of TPH1 in RA-FLS and osteoarthritis (OA)-FLS.

\section{Materials and methods}

Isolation and culture of synovial fibroblasts. FLS were obtained during total knee replacement surgery from patients with RA, who fulfilled the 1987 criteria of the American College of Rheumatology (21), who had never been treated with biological drugs (34 females and 5 males, mean age $64.1 \pm 18.0$ years), and from patients with OA (31 females and 2 males, mean age $71.7 \pm 7.5$ years) between May 2010 and June 2012. Synovial samples were collected from the patients who provided written informed consent for their involvement in the present study, in accordance with the World Medical Association Declaration of Helsinki Ethical Principles for Medical Research Involving Human Subjects. The present study, including consent procedures, was approved by the ethics committee of Kobe University Graduate School of Medicine (Kobe, Japan). Tissue specimens were minced using Cooper surgical scissors and digested in Dulbecco's modified Eagle's medium (DMEM; Gibco Life Technologies, Grand Island, NY, USA), supplemented with $0.2 \%$ collagenase (Sigma-Aldrich, St. Louis, MO, USA), for $2 \mathrm{~h}$ at $37^{\circ} \mathrm{C}$ in an atmosphere containing $5 \% \mathrm{CO}_{2}$. The dissociated synovial cells were subsequently cultured in DMEM, supplemented with $10 \%$ fetal bovine serum (FBS; BioWhittaker ${ }^{\circledR}$, Lonza, Walkersville, MD, USA) and $100 \mathrm{U} / \mathrm{ml}$ penicillin/streptomycin (Meiji Seika Pharma Co., Ltd., Tokyo, Japan). Following an overnight culture, the non-adherent cells were removed, and the adherent cells were further incubated in fresh medium. All experiments were performed using cells from passages 3-7 (6).

Reverse transcription-quantitative polymerase chain reaction $(R T-q P C R)$ analysis. Individual lines of primary cultured RA- and OA-FLS were seeded into 6-well plates at a density of $0.5-1.0 \times 10^{6}$ cells/well in DMEM, supplemented with $10 \%$ FBS, and were cultured for $24 \mathrm{~h}$. The medium was subsequently replaced with serum-free Opti-MEM (Gibco Life Technologies) and the cells were incubated with $1.0 \mu \mathrm{g} / \mathrm{ml}$ recombinant human DcR3-Fc protein (R\&D Systems, Minneapolis, MN, USA) or $1.0 \mu \mathrm{g} / \mathrm{ml}$ control human immunoglobulin $\mathrm{G}$ ( $\mathrm{IgG}) 1$ (R\&D Systems) for $12 \mathrm{~h}$ at $37^{\circ} \mathrm{C}$ in an atmosphere containing $5 \% \mathrm{CO}_{2}$, or with $1.0 \mathrm{ng} / \mathrm{ml} \mathrm{recombi-}$ nant human TNF $\alpha$ (R\&D Systems) or $1.0 \mathrm{ng} / \mathrm{ml}$ recombinant human interleukin (IL)-1 $\beta$ (R\&D Systems) for $24 \mathrm{~h}$ at $37^{\circ} \mathrm{C}$ in an atmosphere containing $5 \% \mathrm{CO}_{2}$. Following incubation, the total RNA was extracted from the cells using a QIAshredder with the RNeasy Mini kit (Qiagen GmbH, Hilden, Germany), according to the manufacturer's instructions.

The total RNA $(2 \mu \mathrm{g})$ was reverse transcribed to first-strand cDNA using an Oligo (dT) primer and a High-Capacity cDNA Reverse Transcription kit (Applied Biosystems Life Technologies, Foster City, CA, USA), according to the manufacturer's instructions. The cycling conditions were as follows: $10 \mathrm{~min}$ at $25^{\circ} \mathrm{C}, 2 \mathrm{~h}$ at $37^{\circ} \mathrm{C}, 5 \mathrm{~min}$ at $85^{\circ} \mathrm{C}$ and $4^{\circ} \mathrm{C}$ thereafter using a PCR thermal cycler (Astec, Fukuoka, Japan).

The relative mRNA expression levels were compared using TaqMan ${ }^{\circledR}$ Real-Time PCR on a StepOne ${ }^{\text {TM }}$ Real-Time PCR system (Applied Biosystems Life Technologies). The cycling conditions were as follows: $50^{\circ} \mathrm{C}$ for $2 \mathrm{~min}, 95^{\circ} \mathrm{C}$ for $10 \mathrm{~min}, 50$ cycles of $95^{\circ} \mathrm{C}$ for $15 \mathrm{sec}$ and $60^{\circ} \mathrm{C}$ for $1 \mathrm{~min}$. Pre-designed primers and probes for TPH1 (Hs00188220_m1) and GAPDH (Hs99999905_m1) mRNA were obtained from Applied Biosystems Life Technologies. GAPDH was used as a control. Comparative analyses of each of these genes in individual patients were performed using a specialized computer program, StepOne ${ }^{\mathrm{TM}}$ Software version 2.1 (Applied Biosystems Life Technologies). All amplifications were performed at least in duplicates. The mRNA expression levels of each gene were calculated using the $2^{-\Delta \Delta \mathrm{Ct}}$ (comparative threshold cycle, or $C_{\mathrm{T}}$ ) method, as detailed by the manufacturer (Applied Biosystems Life Technologies).

Immunohistochemistry. Frozen synovial tissues from patients with RA and OA were cut into $9 \mu \mathrm{m}$ sections using a cryostat (Leica CM3050 S ${ }^{\mathrm{TM}}$; Leica Biosystems, Nussloch, Germany). Mouse anti-human serotonin monoclonal antibody (cat. no. 53842; 1:20 dilution; AnaSpec, Fremont, CA, USA) was applied to the sections and incubated overnight at $4^{\circ} \mathrm{C}$. The HistoFine ${ }^{\circledR}$ Simple Stain ${ }^{\mathrm{TM}}$ kit anti-mouse antibody with peroxidase (cat. no. 414131F; Nichirei Corporation, Tokyo, Japan) was used as a secondary antibody and incubated for $30 \mathrm{~min}$ at room temperature. The sections were developed using HistoFine ${ }^{\circledR}$ Simple Stain 3,3'-diaminobenzidine (Nichirei Corporation), followed by counterstaining with hematoxylin (Muto Pure Chemicals Co., Ltd., Tokyo, Japan). Images of the stained sections were captured using an Axioskop 2 plus (Carl Zeiss, Jena, Germany).

Statistical analysis. For all statistical analyses the program Statcel version 3 (OMS, Tokyo, Japan) was utilized. All data are presented as the mean \pm standard deviation, unless otherwise stated. In all cases, P-values were calculated using a two-tailed Student's t-test. $\mathrm{P}<0.05$ was considered to indicate a statistically significant difference. 
A

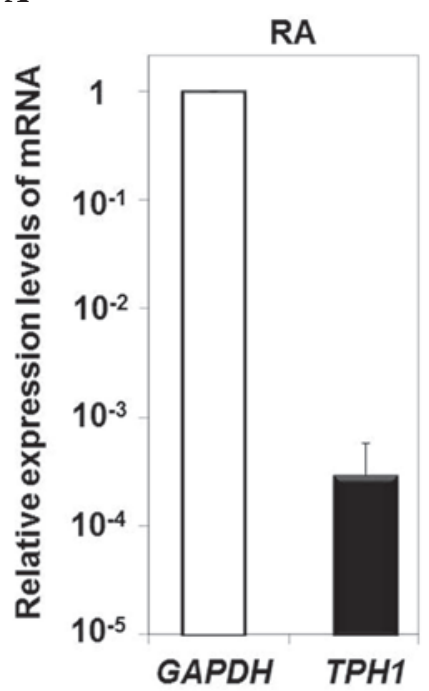

B

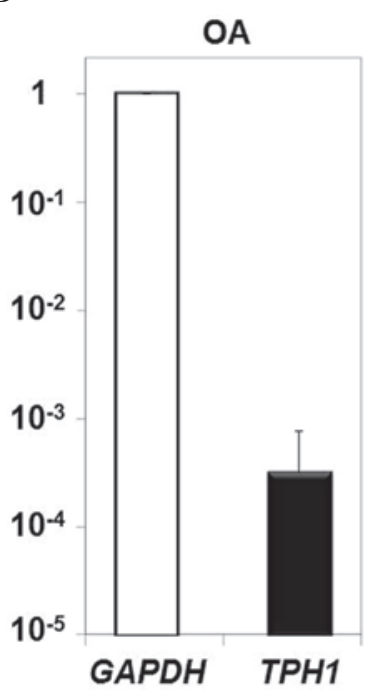

Figure 1. mRNA expression levels of TPH1 in RA- and OA-FLS. Reverse trasncription-quantitative polymerase chain reaction analysis of the mRNA expression levels of TPH1 in (A) RA-FLS and (B) OA-FLS. The values were normalized against the mRNA expression of GAPDH (n=39 for RA and 33 for OA), $T P H 1$, tryptophan hydroxylase 1; RA, rheumatoid arthritis; OA, osteoarthritis; FLS, fibroblast-like synoviocytes.
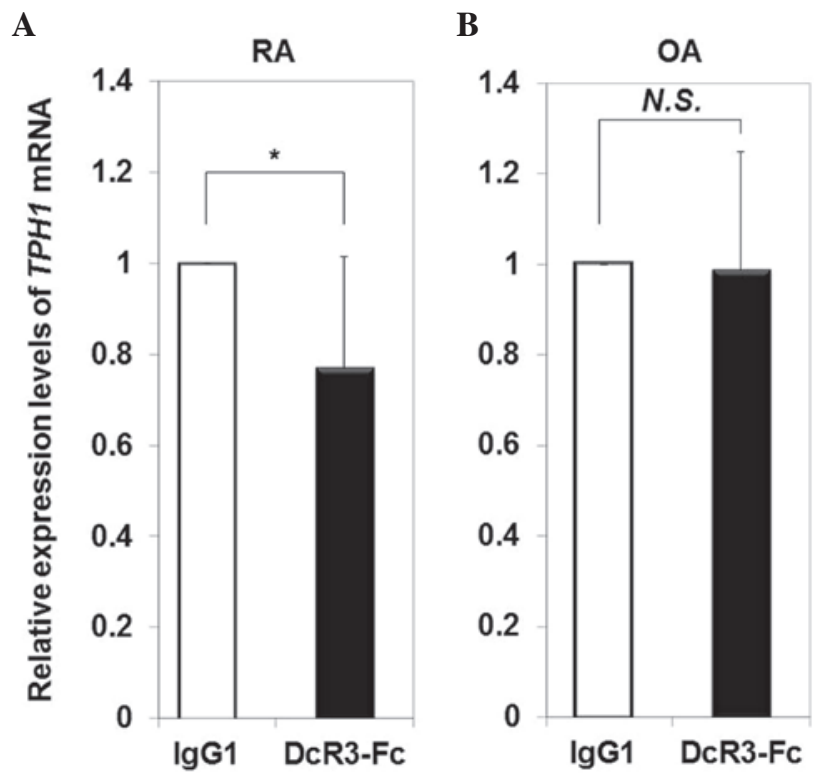

Figure 2. Effects of DcR3 on the expression of TPH1 in RA- and OA-FLS. (A) RA-FLS and (B) OA-FLS were stimulated with 1.0 $\mu \mathrm{g} / \mathrm{ml}$ IgG1 or DcR3-Fc for $12 \mathrm{~h}$. The relative mRNA expression levels of $T P H 1$ were determined using reverse transcription-quantitative polymerase chain reaction. The cells stimulated with control IgG1 were assigned a value of 1 ( $\mathrm{P}<0.05$, compared with the IgG1 treated cells; n=13 for RA and 13 for OA). DcR3-Fc, decoy receptor 3-Fc protein; IgG1, immunoglobulin G1; TPH1, tryptophan hydroxylase 1; RA, rheumatoid arthritis; OA, osteoarthritis; FLS, fibroblast-like synoviocytes; N.S., non-significant.

\section{Results}

mRNA expression levels of TPH1 in RA- or OA-FLS. The present study initially aimed to detect the mRNA expression levels of TPH1 in RA- and OA-FLS. RT-qPCR analysis demonstrated that TPHI mRNA was expressed in both RAand OA-FLS (Fig. 1).

Disease specificity of downregulation the mRNA expression levels of TPH1 in RA-FLS by DcR3. The mRNA expression levels of TPHI in RA- and OA-FLS stimulated with DcR3-Fc were compared with the expression levels in cells incubated with control IgG1. The mRNA expression levels of TPHI were significantly decreased (0.77-fold) in RA-FLS following treatment with DcR3-Fc (Fig. 2A), whereas the expression of TPH1 in OA-FLS was not influenced following treatment with DcR3-Fc (Fig. 2B).

Effects of inflammatory cytokines on the mRNA expression levels of TPH1 in RA- and OA-FLS. The mRNA expression levels of TPH1 in RA- and OA-FLS stimulated with TNF $\alpha$ or IL-1 $\beta$ were compared with the expression levels in the cells incubated with serum-free Opti-MEM only. Both TNF $\alpha$ and IL-1 $\beta$ suppressed the mRNA expression levels of TPHI in 
A

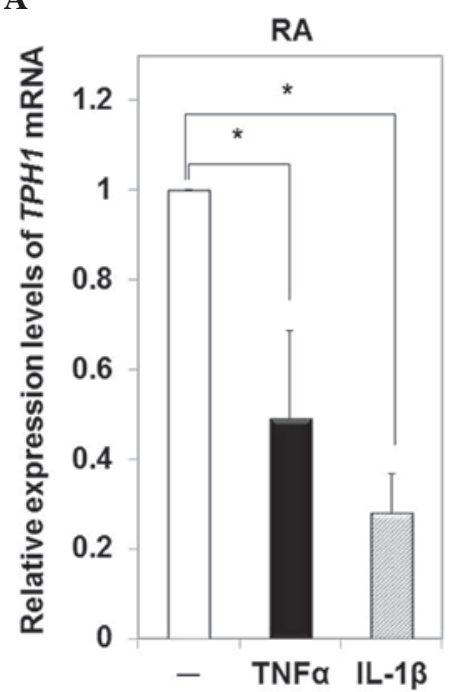

B

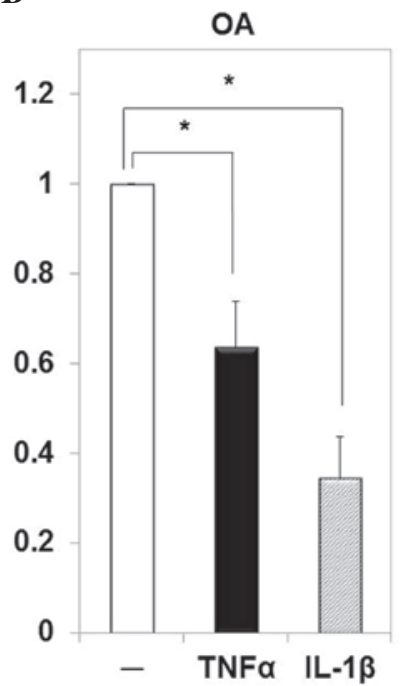

Figure 3. Effects of inflammatory cytokines on the expression of TPH1 in RA- and OA-FLS. (A) RA-FLS and (B) OA-FLS were stimulated with 1 ng/m1 TNFo or IL-1 $\beta$. Following incubation for $24 \mathrm{~h}$, the relative mRNA expression levels of TPHI were determined by reverse transcription-quantitative polymerase chain reaction. The untreated cells were assigned a value of $1\left({ }^{*} \mathrm{P}<0.05\right.$, compared with the untreated; $\mathrm{n}=18$ for RA with TNF $\alpha$ and 12 with IL-1 $\beta$, and $n=10$ for $\mathrm{OA}$ with TNF $\alpha$ and 12 with IL-1 $\beta$ ). TPH1, tryptophan hydroxylase 1; RA, rheumatoid arthritis; OA, osteoarthritis; FLS, fibroblast-like synoviocytes; TNF, tumor necrosis factor; IL, interleukin.

A

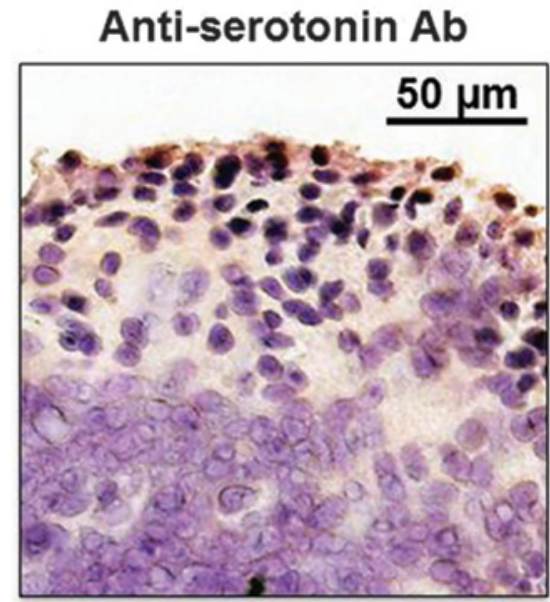

\section{Control Ig}

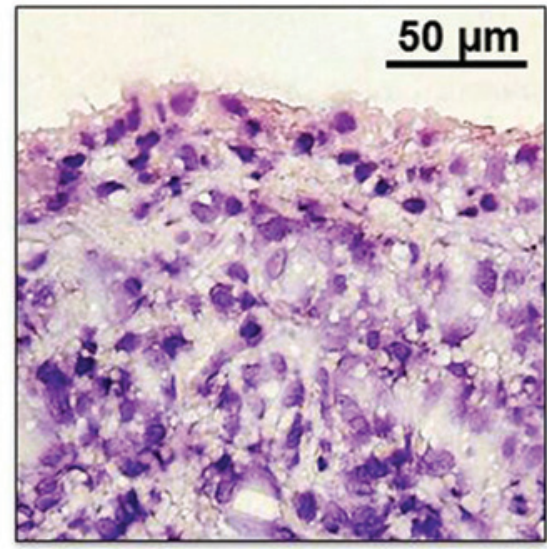

B

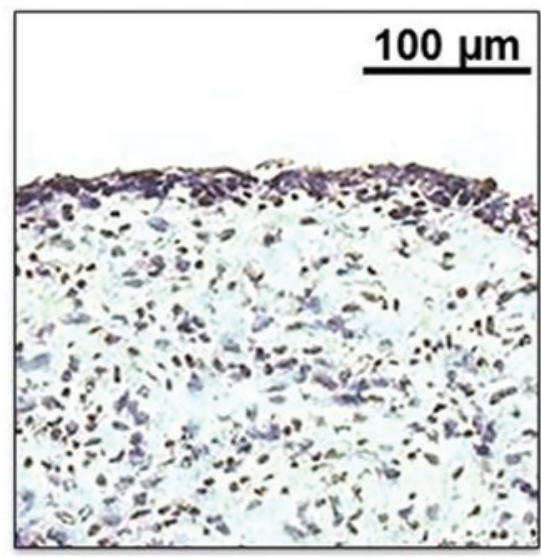

$O A$

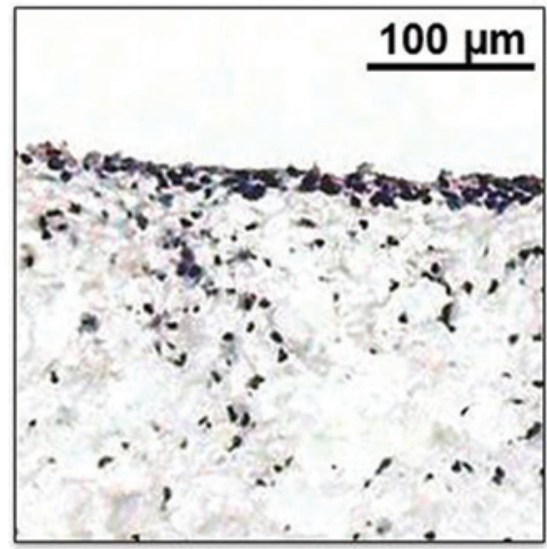

Figure 4. (A) Immunohistochemical analysis of the expression of serotonin in RA synovial tissue. The images of RA synovial tissue sections were analyzed by immunohistochemistry using an anti-serotonin antibody or negative control Ig. The slides were counterstained with hematoxylin (scale bar, $50 \mu \mathrm{m}$ ). (B) Immunohistochemical comparison of serotonin expression and localization in RA and OA synovial tissue. The images of synovial tissue sections from patients with RA and OA were analyzed by immunohistochemistry using an anti-serotonin antibody. The slides were counterstained with hematoxylin (scale bars, $100 \mu \mathrm{m})$. RA, rheumatoid arthritis; OA, osteoarthritis; Ig, immunoglobulin. 
RA-FLS (0.49-fold and 0.28-fold, respectively; Fig. 3A), as well as in OA-FLS (0.63-fold and 0.34-fold, respectively; Fig. 3B).

Immunohistochemical analysis of serotonin in $R A$ and $O A$ synovial tissue. To confirm that the serotonin synthesis pathway was intact in the RA- and OA-FLS, the expression and localization of serotonin was detected in RA and OA synovial tissue by immunohistochemical analysis. Immunohistochemical analysis demonstrated that serotonin was specifically expressed in the multi-layered lining synovial cells of RA synovial tissue (Fig. 4A). Serotonin was also primarily present in the outer layer lining cells of OA synovial tissue (Fig. 4B). Conversely, serotonin was present at lower levels in the sublining layer of both RA and OA synovial tissue (Fig. 4B).

\section{Discussion}

The present study demonstrated that TPH1 was expressed in RA-FLS and its expression was downregulated by DcR3. In the serotonin synthesis pathway, L-tryptophan is hydroxylated into L-5-hydroxytryptophan by TPH, which is then decarboxylated into serotonin by an L-amino acid decarboxylase (22). Since TPH is the rate-limiting enzyme of serotonin synthesis (22), these data suggest that DcR3 may regulate serotonin synthesis in synovial cells, and thereby regulate peripheral serotonin levels. The present study demonstrated that serotonin is synthesized in RA-FLS. Previous studies have suggested that peripheral serotonin, which is synthesized through TPH1 activity, has pleiotropic effects, including functions in the immune system (23), vasoconstriction (24), modulating inflammatory pain $(25)$ and bone physiology $(24,25)$. In addition, serotonin regulates osteoblast proliferation and bone formation (25), and osteoclast differentiation and activity (26). The regulation of the expression of TPH1 and its presumed subsequent effects on serotonin levels by DcR3 in RA-FLS may therefore, have important consequences for RA.

The results of the present study demonstrated that serotonin was highly expressed in the disease-specific multi-layered synovial lining cells of RA, and in the outer layer lining cells of OA, however, it was weakly expressed in the sublining cells. These results suggested that serotonin may have a certain role in synovial lining cells, particularly in over-proliferating RA synovial cells. Investigation of the synovial fluid and cartilage may assist in increasing our understanding regarding the effects of serotonin on arthritis, and on the destruction of cartilage and bone. Further studies on other tissue types, including cartilage or synovial fluid, may be required to elucidate the role of serotonin in bone metabolism.

In the present study, the inflammatory cytokines, $\mathrm{TNF} \alpha$ and IL-1 $\beta$, suppressed the mRNA expression levels of TPHI in RA- and OA-FLS, however, DcR3 only suppressed the mRNA expression of TPH1 in RA-FLS. These results indicated that the mRNA expression of TPHI in RA-FLS was downregulated by DcR3 in a disease-specific manner. Since the concentration of DcR3 in the sera and synovial fluid of patients with RA is significantly higher, as compared with patients with OA (27), the higher levels of DcR3 may lead to decreased levels of peripheral serotonin via DcR3-mediated suppression of the mRNA expression of TPHI. The present study also provided important information regarding the influence of inflamma- tory cytokines on the expression levels of TPH1 in RA- and OA-FLS, and of the expression of serotonin in the synovial tissue of RA and OA.

In conclusion, the results of the present study suggested that DcR3 may affect the expression of peripheral serotonin in rheumatoid synovial tissue by regulating the mRNA expression of TPH1 in RA-FLS. These results indicated that DcR3 may be involved in the pathogenesis of RA, particularly in processes including modulation of inflammatory pain and bone remodeling. In addition to DcR3, TPH1 may also be a potential therapeutic target for the treatment of RA.

\section{Acknowledgements}

The present study was supported by a grant-in-aid in the form of a health science research grant from the Japanese Ministry of Education, Science, and Culture (no. 24592261). The findings of the present study were presented at the 2013 American College of Rheumatology/Association of Rheumatology Health Professionals Annual Meeting, October 25-30, 2013 (San Diego, CA, USA).

\section{References}

1. Chou CT, Yang JS and Lee MR: Apoptosis in rheumatoid arthritis - expression of Fas, Fas-L, p53, and Bcl-2 in rheumatoid synovial tissues. J Pathol 193: 110-116, 2001.

2. Tak PP, Zvaifler NJ, Green DR and Firestein GS: Rheumatoid arthritis and p53: How oxidative stress might alter the course of inflammatory diseases. Immunol Today 21: 78-82, 2000.

3. Yamanishi Y, Boyle DL, Rosengren S, Green DR, Zvaifler NJ and Firestein GS: Regional analysis of p53 mutations in rheumatoid arthritis synovium. Proc Natl Acad Sci USA 99: 10025-10030, 2002.

4. Alamanos Y and Drosos AA: Epidemiology of adult rheumatoid arthritis. Autoimmun Rev 4: 130-136, 2005.

5. Zhu P, Lu N, Shi ZG, Zhou J, Wu ZB, Yang Y, Ding J and Chen ZN: CD147 overexpression on synoviocytes in rheumatoid arthritis enhances matrix metalloproteinase production and invasiveness of synoviocytes. Arthritis Res Ther 8: R44, 2006.

6. Hayashi S, Miura Y, Nishiyama T, Mitani M, Tateishi K, Sakai Y, Hashiramoto A, Kurosaka M, Shiozawa S and Doita M: Decoy receptor 3 expressed in rheumatoid synovial fibroblasts protects the cells against Fas-induced apoptosis. Arthritis Rheum 56: 1067-1075, 2007

7. Pitti RM, Marsters SA, Lawrence DA, Roy M, Kischkel FC Dowd P, Huang A, Donahue CJ, Sherwood SW, Baldwin DT, et al: Genomic amplification of a decoy receptor for Fas ligand in lung and colon cancer. Nature 396: 699-703, 1998.

8. Bai C, Connolly B, Metzker ML, Hilliard CA, Liu X, Sandig V, Soderman A, Galloway SM, Liu Q, Austin CP and Caskey CT: Overexpression of $\mathrm{M} 68 / \mathrm{DcR} 3$ in human gastrointestinal tract tumors independent of gene amplification and its location in a four-gene cluster. Proc Natl Acad Sci USA 97: 1230-1235, 2000.

9. Yang CR, Wang JH, Hsieh SL, Wang SM, Hsu TL and Lin WW: Decoy receptor 3 (DcR3) induces osteoclast formation from monocyte/macrophage lineage precursor cells. Cell Death Differ 11 (Suppl 1): S97-S107, 2004.

10. Hsu MJ, Lin WW, Tsao WC, Chang YC, Hsu TL, Chiu AW, Chio CC and Hsieh SL: Enhanced adhesion of monocytes via reverse signaling triggered by decoy receptor 3. Exp Cell Res 292: 241-251, 2004.

11. Tateishi K, Miura Y, Hayashi S, Takahashi M and Kurosaka M: DcR3 protects THP-1 macrophages from apoptosis by increasing integrin alpha4. Biochem Biophys Res Commun 389: 593-598, 2009.

12. Shi G, Wu Y, Zhang J and Wu J: Death decoy receptor TR6/DcR3 inhibits T cell chemotaxis in vitro and in vivo. J Immunol 171: 3407-3414, 2003.

13. Tsuji S, Hosotani R, Yonehara S, Masui T, Tulachan SS Nakajima S, Kobayashi H, Koizumi M, Toyoda E, Ito D, et al: Endogenous decoy receptor 3 blocks the growth inhibition signals mediated by Fas ligand in human pancreatic adenocarcinoma. Int J Cancer 106: 17-25, 2003. 
14. Yu KY, Kwon B, Ni J, Zhai Y, Ebner R and Kwon BS: A newly identified member of tumor necrosis factor receptor superfamily (TR6) suppresses LIGHT-mediated apoptosis. J Biol Chem 274: 13733-13736, 1999.

15. Migone TS, Zhang J, Luo X, Zhuang L, Chen C, Hu B, Hong JS, Perry JW, Chen SF, Zhou JX, et al: TL1A is a TNF-like ligand for DR3 and TR6/DcR3 and functions as a T cell costimulator. Immunity 16: 479-492, 2002.

16. Takahashi M, Miura Y, Hayashi S, Tateishi K, Fukuda K and Kurosaka M: DcR3-TL1A signalling inhibits cytokine-induced proliferation of rheumatoid synovial fibroblasts. Int $\mathrm{J}$ Mol Med 28: 423-427, 2011.

17. Fukuda K, Miura Y, Maeda T, Takahashi M, Hayashi S and Kurosaka M: Decoy receptor 3 regulates the expression of various genes in rheumatoid arthritis synovial fibroblasts. Int J Mol Med 32: 910-916, 2013.

18. Ducy P and Karsenty G: The two faces of serotonin in bone biology. J Cell Biol 191: 7-13, 2010.

19. Yadav VK and Ducy P: Lrp5 and bone formation: A serotonin-dependent pathway. Ann NY Acad Sci 1192: 103-109, 2010.

20. Voog O, Alstergren P, Leibur E, Kallikorm R and Kopp S: Immediate effects of the serotonin antagonist granisetron on temporomandibular joint pain in patients with systemic inflammatory disorders. Life Sci 68: 591-602, 2000.
21. Arnett FC, Edworthy SM, Bloch DA, McShane DJ, Fries JF, Cooper NS, Healey LA, Kaplan SR, Liang MH, Luthra HS, et al: The American Rheumatism Association 1987 revised criteria for the classification of rheumatoid arthritis. Arthritis Rheum 31: 315-324, 1988.

22. Lovenberg W, Jequier E and Sjoerdsma A: Tryptophan hydroxylation: Measurement in pineal gland, brainstem, and carcinoid tumor. Science 155: 217-219, 1967.

23. Geba GP, Ptak W, Anderson GM, Paliwal V, Ratzlaff RE, Levin J and Askenase PW: Delayed-type hypersensitivity in mast cell-deficient mice: Dependence on platelets for expression of contact sensitivity. J Immunol 157: 557-565, 1996.

24. Walther DJ and Bader M: A unique central tryptophan hydroxylase isoform. Biochem Pharmacol 66: 1673-1680, 2003.

25. Karsenty G and Yadav VK: Regulation of bone mass by serotonin: Molecular biology and therapeutic implications. Annu Rev Med 62: 323-331, 2011.

26. Gustafsson BI, Thommesen L, Stunes AK, Tommeras K, Westbroek I, Waldum HL, Slørdahl K, Tamburstuen MV, Reseland JE and Syversen U: Serotonin and fluoxetine modulate bone cell function in vitro. J Cell Biochem 98: 139-151, 2006.

27. Hayashi S, Miura Y, Tateishi K, Takahashi M and Kurosaka M: Decoy receptor 3 is highly expressed in patients with rheumatoid arthritis. Mod Rheumatol 20: 63-68, 2010. 